ORIGINAL ARTICLE

\title{
Knowledge and Health Problems Related to Health Behavior among the Secondary School Children in Rural Community of Dhamrai Upazila, Dhaka
}

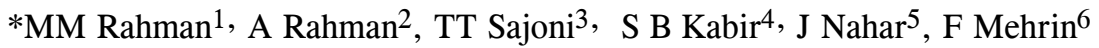 \\ ${ }^{1}$ Prof. Dr. Md. Mahfuzar Rahman, Professor and Head, Dept. of Community Medicine, AKMMC \\ ${ }^{2}$ Dr. Md. Atiqur Rahman, Associate Professor (c.c), Dept. of Community Medicine, AKMMC \\ ${ }^{3}$ Dr. Tabassum Tahmin Sajani, Assistant professor, Dept. of Community Medicine, AKMMC \\ ${ }^{4}$ Dr. Saba Binta Kabir, Lecturer, Dept. of Community Medicine, AKMMC \\ ${ }^{5}$ Dr. Jesmin Naher, Lecturer, Dept. of Community Medicine, AKMMC \\ ${ }^{6}$ Dr. Farnaz Mehrin, Lecturer, Dept of Community Medicine, AKMMC
}

*Corresponding Author

\begin{abstract}
In Bangladesh, there are 18,756 secondary schools in which 17.91 million students are enrolled. School children are more vulnerable to be attacked by various types of communicable diseases due to poor health behaviors. The aim of this study was to find out knowledge and health problems related to health behavior among the secondary school children. This descriptive cross sectional study was carried among 795 secondary school children by purposive sampling from 22nd to 24th January 2014 in different school s of Dhamrai Upazila, Dhaka. Data were collected on a pretested questionnaire by face to face interview. Data were analyzed manually and by using computer. The study revealed that majority of the respondents were Muslims by religion, $45 \%$ had education level Class VII and mean age was $13 \pm 1.7$ years. Most of them $45 \%$ \& $40 \%$ students father's and Mothers education level respectively was HSC and above. About 50\% students father's occupation were service and 33\% were businessman. Mostly about $79 \%$ students mother's were housewife. Among all about $71 \%$ students were found having 2-3 brothers and sisters respectively. About 20\%, 9\% and 7\% respondents don't agree on drinking clean boiled water, avoidance of smoking and care of nails as a healthy behavior. $25 \%, 13 \%$ and $11 \%$ respondents don't practice drinking clean boiled, regular brushing of teeth and care of nails. About $95 \%, 74 \%$ and $67 \%$ learned on health behavior from family teachers and text books respectively. About 19\%, 14\% and 10\% students were suffering from common cold, unhealthy hair and itching respectively. Knowledge regarding health behavior among the secondary school children was found still worse. The study recommends more effective implantation of awareness program to improve knowledge regarding health behavior.
\end{abstract}

Key Words: Knowledge, Practice, Behavior, Secondary school, Students, Personal hygiene

\section{Introduction}

Personal hygiene is the science of healthy-living of an individual. The term personal hygiene includes all those personal factors, which influence the health and wellbeing of an individual. It comprises a broad range of day to day activities such as bathing, clothing, washing hands and toilet; care of nails, feet and teeth; spitting, coughing, sneezing, personal appearance and inculcation of clean habits. Training in personal hygiene should begin at a very early age and must be carried through school age. Snow reported that children with proper hand washing practices are less likely to report gastrointestinal and respiratory symptoms ${ }^{1}$. In addition, hand washing with soap has been reported to reduce diarrheal morbidity by $44 \%$ and respiratory infections by $23 \%^{2}$. There-fore, it is clearly evident that the aim of personal hygiene is not only to promote the standards of personal cleanliness within the setting of the condition where people live, but also to reduce the prevalence and incidence of communicable diseases. 
Personal habits are discrete and independently modifiable. Individuals can voluntarily alter such behavior to maintain good personal hygiene. One of the main problems of Bangladesh is illiteracy. Forty four percent people of Bangladesh are reportedly illiterate ${ }^{3}$. It is unknown to them that simply practice of hand washing and provision of potable drinking water in adequate quantity can eliminate most water borne and water related diseases $^{4}$. Since about $90 \%$ of infections are carried to the body through the mouth with water, food, dirt etc., the importance of personal cleanliness and clean habits is obvious ${ }^{5}$.

Infection and malnutrition form a vicious circle and retard children's physical development. Repeated attacks of infections often compound the existing poor health of children, compromising children's attendance and performance at school and not uncommonly, can result in death. The condition may even be worse in a slum community with poor socio-economic condition and compromised living situation. The origins of many of the illnesses of adulthood also have their roots in the health behaviors of childhood and adolescence. However, majority of the childhood illnesses are preventable by promotion of hygienic practices among school children through proper health education by their parents and teachers ${ }^{6}$. Children in their primary schooling age can learn specific health-promoting behaviors, even if they do not fully understand the connections between illness and behavior ${ }^{7}$.

In Bangladesh, there are 18,756 secondary schools in which 17.191 million students are enrolled ${ }^{8}$. School as socializing institution for children and adolescents play a vital role in the development of healthy citizen. School health education program can play a vital role in changing health behavior of the people. Health management can easily be spread into the family, community through the school students.

The present study was aimed to find out knowledge and health problems related to health behavior among the secondary school children and being intended to support a change of the role of the community from passive recipient to active participation in health development process by identifying their own problems.

\section{Methodology}

This was a descriptive cross sectional study carried out in Dhamrai Upazila, Dhaka under Dhamrai union in Taltola, Choibaria, Kumrail, Islampur, Chandrail, Ambagan, Palara and Sadamath villages during the period $22^{\text {nd }}$ to $24^{\text {th }}$ January, 2014 for data collection. Secondary school children of class VI to class VIII during data collection period were the study population. Total size of the sample was 795 and purposive in nature. Duly pre-tested structured questionnaire and check list were the instruments for data collection. It was collected through face to face interview by $4^{\text {th }}$ year MBBS students (AKMMC -03) of Anwer Khan Modern Medical College, Dhanmondi, Dhaka with prior filling up a consent form and signed by the respondent as a part of ethical consideration. It was processed and analyzed manually and by using computer.

\section{Results}

Table-I: Distribution of respondents by age \& sex n $=795$

\begin{tabular}{cccc}
\hline \multicolumn{2}{l}{ Age in yearsNumber of respondents } & \multicolumn{2}{l}{ Sex } \\
$10-12$ & 276 & Male & 323 \\
& $(35)$ & & $(41)$ \\
$13-15$ & 468 & Female & 472 \\
& $(59)$ & & $(59)$ \\
$16-18$ & 51 & Total & 795 \\
& $(6)$ & & $(100)$ \\
Total & 795 & & \\
& $(100)$ & & \\
\end{tabular}

About 59\% respondents were found within age of 13-15 years. Mean age : 13years SD : 1.7 with male $41 \%$ and female $59 \%$.

(N.B: Figures in the parenthesis indicate percentage)

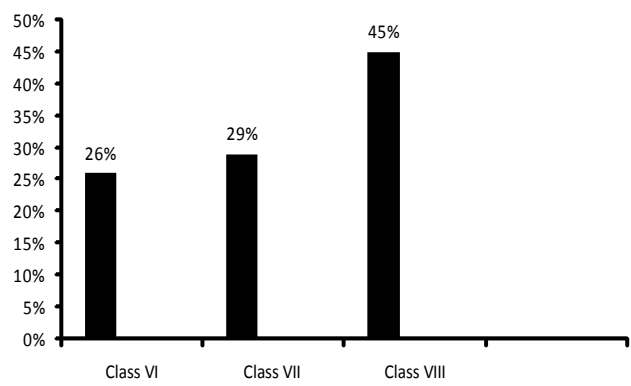

Figure-1: Simple Bar diagram showing distribution of respondents by level of education

Figure-1: shows that about 26\%, 29\% \& 45\% respondents were found students of Class VI, Class VII \& Class VIII respectively. 
Table-II: Distribution of respondents by father's and mother's level of educationn $=795$

\begin{tabular}{ccccc}
\hline Level of & \multicolumn{2}{c}{ Father's } & \multicolumn{2}{c}{ Mother's } \\
\hline education & $\begin{array}{c}\text { Number of } \\
\text { respondents } \\
57\end{array}$ & Percentage & $\begin{array}{c}\text { Number of } \\
\text { respondents } \\
96\end{array}$ & Percentage \\
Illiterate & 202 & 13 & 206 & 12 \\
Primary & 302 & 38 & 315 & 40 \\
Secondary & 334 & 42 & 178 & 22 \\
$\begin{array}{c}\text { HSC \& } \\
\text { above } \\
\text { Total }\end{array}$ & 795 & 100 & 795 & 100 \\
\hline
\end{tabular}

HSC and above level of education was found in $42 \%$ \& $22 \%$ student's father and mother.

Table-III: Distribution of respondents by father's and mother's level of educationn $=795$

\begin{tabular}{ccccc}
\hline Occupation & \multicolumn{2}{c}{ Fathes' } & \multicolumn{2}{c}{ Mother's } \\
\hline & $\begin{array}{c}\text { Number of } \\
\text { respondents } \\
400\end{array}$ & 50 & 129 & 16 \\
Service & 400 rentage & $\begin{array}{c}\text { Number of } \\
\text { respondents }\end{array}$ & Percentage \\
Business & 260 & 33 & 03 & .3 \\
Agriculture & 25 & 3 & 00 & 00 \\
Day laborers & 47 & 6 & 24 & 3 \\
Housewife & & & 627 & 79 \\
Others & 63 & 8 & 12 & 1.5 \\
Total & 795 & 100 & 795 & 100 \\
\hline
\end{tabular}

About 50\% students father's occupation were service and 33\% were businessman. Mostly about $79 \%$ students mother's were housewife.

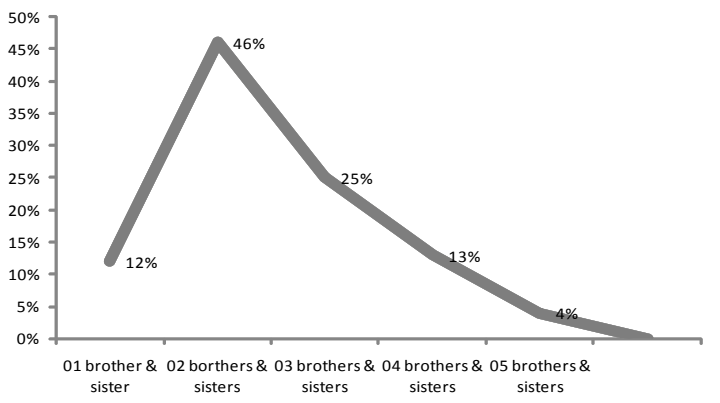

Figure-2 : Line diagram showing distribution of respondents by number of brothers \&sisters

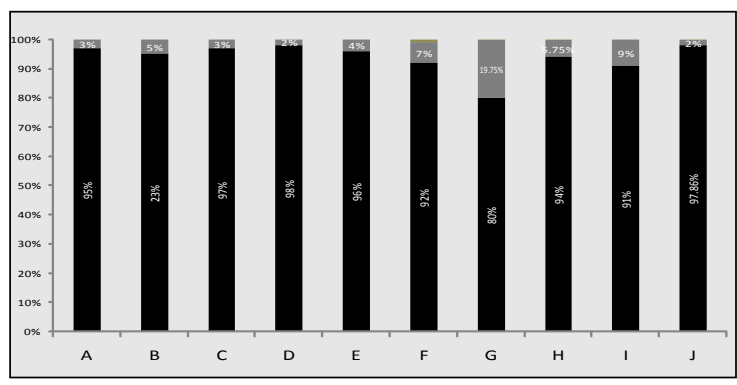

Figure 03 shows that $46 \% \& 25 \%$ students were found having $2 \& 3$ brothers and sisters respectively.

Figure 03 : Component Bar diagram showing distribution of respondents by knowledge on health behavior

(NB: A: Regular bathing,

D: Use of sanitary latrine or toilet

G: Drinking clean \& boiled water

B: wearing clean clothes;

E: Regular brushing of teeth

$\mathrm{H}$ : Regular sleeping in time

C: Regular washing of hands \& feet;

F: Care of nails,

I: Avoidance of smoking,

$\mathrm{J}$ : Wearing of shoes or sandel on foot.)

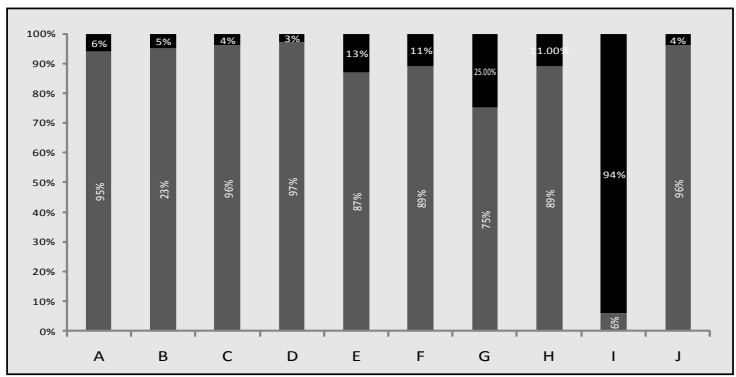

Figure-4 : Component Bar diagram showing distribution of respondents by practice of health behavior

(NB: A: Regular bathing,

D: Use of sanitary latrine or toilet

G: Drinking clean \& boiled water

B: wearing clean clothes;

E: Regular brushing of teeth

$\mathrm{H}$ : Regular sleeping in time

C: Regular washing of hands \& feet;

F: Care of nails,

I: Smoking,

$\mathrm{J}$ : Wearing of shoes or sandel on foot.

Figure-4 shows that $25 \%, 13 \%$ \& $11 \%$ respondents don't practice drinking clean-boiled water, regular brushing of teeth $\&$ care of nails. 


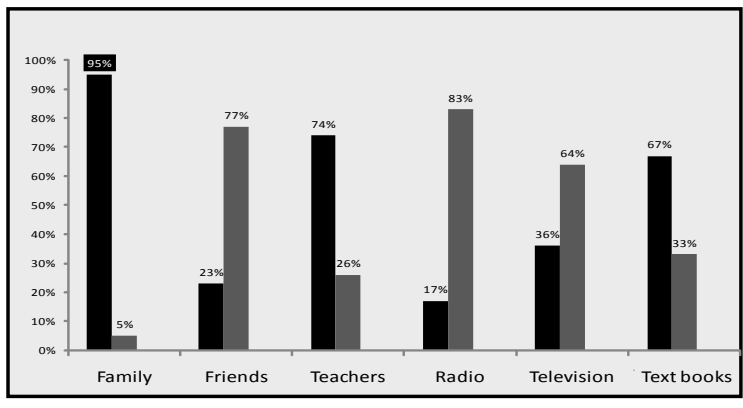

Figure-6 : Multiple Bar diagram showing distribution of respondents by sources of information on health behavior

Figure-6 shows that about 95\%, 74\% \& $67 \%$ learned on health behavior from family, teachers \& text books respectively.

\section{Discussion}

The literacy rate and women education in Bangladesh is growing up gradually due to ongoing awareness among government and NGO's ${ }^{9}$ and the literacy rate of parents as found in this study is higher than that of national standard $55.9 \%$ as reported by $\mathrm{UNDP}^{3}$. The participation of boys and girls in secondary education observed here is similar to the findings of Begum ${ }^{10}$, who conducted her study in Rotary school and Provati School in Khalispur at Khulna and reported the participation of boys and girls as $46.4 \%$ and $53.6 \%$ respectively with the mean age of 14.6 years.

About 50\% students father's occupation were service and $33 \%$ were businessman. Mostly about $79 \%$ students' mothers were housewife. A comparable finding was revealed by the Centre for Integrated Rural Development of Asia and pacific were majority of women $82 \%$ in rural area were found unpaid family workers ${ }^{11}$. About $71 \%$ students were found having 2-3 numbers of brothers and sisters and $12 \%$ students were found having 01 brother or sister.

In the present study, a trend in increase in the knowledge of the students regarding personal hygiene was observed. In addition, the knowledge of the students regarding the source of safe water for drinking, bathing and washing as documented in this study was found higher than the previous study reported by Begum in
Rotary school and provati school in Khalispur at Khulna ${ }^{10}$. This may be due to increased awareness among people about personal hygiene and government initiatives through print and electronic media.

This study also showed more students $97.7 \%$ were found to take bath daily compared to the earlier work of Rahman who performed a study regarding the practice of personal hygiene among school going and non-school going students in Voberchar Owagir Ali High Scchool of Munshigonj district in 2001 and found $85.8 \%$ took bath daily. As stated earlier, this increased tendency of students to take bath in recent years could be related with the increased awareness among the parents about personal hygiene ${ }^{12}$.

About $95 \%, 74 \%$ \& $67 \%$ students learned on healthy behavior from their family, teacher \& text books respectively. Regarding health problems related to poor health behavior only $19 \%, 14 \%$ \& $10 \%$ respondents were suffering from common cold, unhealthy hair and Itching respectively. This finding varies with the findings of the survey of BDHS which estimated $70 \%$ rural students suffered from scabies, malnutrition, ear discharge, dental caries ${ }^{13}$. This discrepancy may be justified with the logic that this survey was carried out with a small sample size in a semi urban while BDHS conducted country wide survey among large group of people.

\section{Conclusion}

Health of school children is very important issue in Bangladesh as well as in the world. The study concludes that an increase in the trend of knowledge and practice about health behavior was observed among the secondary school children with some exceptions.

\section{Recommendations}

Considering the findings of the present study, there are following recommendations:

- $\square$ Attention needed on safe drinking water, avoiding smoking, care of nails and tooth brushing.

- Family and school teachers need motivation towards improved health practice. 
- Family members and teachers can act as role model towards positive health habits.

- An in-depth large scale study on health habits and problems is needed to improve school health program in future.

\section{Acknowledgement}

It is our pleasure to acknowledge Principal \& Vice-principal of Anwer Khan Modern Medical College to support in conducting this study. We also gratefully acknowledge Director of NIPSOM \& his support staff at Dhamrai THC in providing accommodation \& guidance during our stay at their premises. We are thankful for the support staff of Dhamrai THC as well. Thanks to our AKMMC-03 batch, students for their hard work from the very beginning in conducting and implementing this study protocol and their active participation for data collection in particular. Last but not least the people of the study area are gratefully acknowledged as key informants.

\section{References}

1. Snow M, GL White HS Kim. Inexpensive and timeefficient hand hygiene interventions increase elementary school children's hand hygiene rates. J Sch Health 2008; 78: 230-233.

2. Curtis VA, LO Danquah RV Aunger. Planned, motivated and habitual hygiene behaviour: an eleven country review. Health Educ Res 2009; 4: 655-673.

3. UNDP. 2011. List of Countries by Literacy rate, United Nations Development Programme Report, 2011.

4. Rashid KM, MD Khabiruddin H sayeed, 2004. Text Book of Community Medicine and Public health, RKH Publishers, 4th Ed, pp: 309.

5. Ghosh BN, 1969. Treatise on hygiene and Public Health, Scientific Publishing Company, 11th Ed, pp: 320.
6. Department of Drinking Water Supply, Ministry of Rural Development, Government of India. Technical Note Series. School water supply, sanitation \& hygiene education: India. New Delhi: Department of Drinking Water Supply; 2004. Retrieved from http://www.ddws.gov.in/sites/upload_files/ddws/file s/pdf/pdf/TechNoteSSHE_0.pdf

7. Richmond JB, Kotelchuck M. Personal health maintenance for children. West $\mathrm{J}$ Med 1984;141:816-23.

8. BANBEIS, 2008. (http://www.banbeis.gov.bd/db_bb/ secondary_education_1.htm)

9. Bangla, 2000. (http://www.bangla 2000.com/ bangladesh/ education. shtm)

10. Begum S, 2000. Knowledge regarding personal hygiene among the students and hygienic status of two selected secondary schools. Dhaka (NIPSOM): Bangladesh.

11. Bangladesh Bureau of Statistics (BBS). Sample Vital Registration System (SVRS), Bangladesh; 2008.

12. Rahman A, 2001. A study on practice regarding personal hygiene among school going and nonschool going children in a selected rural area. Dhaka (NIPSOM): Bangladesh.

13. Chowdhury SNM, Kabir M, Hossain A. MR Programme in Bangladesh: Challenges for the Future". Background paper prepared for the project. A Situation Analysis of Bangladesh Menstrual Regulation Programme. Reproductive Health Alliance. 2002. 